\title{
Tracing Hidden Herbivores: Time-Resolved Non-Invasive Analysis of Belowground Volatiles by Proton-Transfer-Reaction Mass Spectrometry (PTR-MS)
}

\author{
Holger Danner • Devasena Samudrala • \\ Simona M. Cristescu • Nicole M. Van Dam
}

Received: 7 February 2012 /Revised: 18 April 2012 / Accepted: 24 April 2012 /Published online: 18 May 2012

(C) The Author(s) 2012. This article is published with open access at Springerlink.com

\begin{abstract}
Root herbivores are notoriously difficult to study, as they feed hidden in the soil. However, root herbivores may be traced by analyzing specific volatile organic compounds (VOCs) that are produced by damaged roots. These VOCs not only support parasitoids in the localization of their host, but also may help scientists study belowground plant-herbivore interactions. Herbivore-induced VOCs are usually analyzed by gas-chromatography mass spectrometry (GC-MS), but with this off-line method, the gases of interest need to be preconcentrated, and destructive sampling is required to assess the level of damage to the roots. In contrast to this, proton-transfer-reaction mass spectrometry (PTR-MS) is a very sensitive on-line, non-invasive method. PTR-MS already has been successfully applied to analyze VOCs produced by aboveground (infested) plant parts. In this review, we provide a brief overview of PTR-MS and illustrate how this technology can be applied to detect specific root-herbivore induced VOCs from Brassica plants. We also specify the advantages and disadvantages of PTRMS analyses and new technological developments to overcome their limitations.
\end{abstract}

Keywords Chemical ecology $\cdot$ Root herbivory $\cdot$ Trace gas analysis $\cdot$ Induced indirect defense $\cdot$ Mass spectrometry $\cdot$ Volatile organic compound (VOC)

H. Danner $(\bowtie) \cdot$ N. M. Van Dam

Department of Ecogenomics, Institute for Water and Wetland

Research (IWWR), Radboud University,

PO Box 9010, 6500 GL, Nijmegen, The Netherlands

e-mail: h.danner@science.ru.nl

D. Samudrala $\cdot$ S. M. Cristescu

Life Science Trace Gas Facility, Institute for Molecules and

Materials, Radboud University,

Nijmegen, The Netherlands

\section{Introduction}

Belowground herbivores can cause substantial damage to plant roots, which in many cases has a more severe impact on plant fitness than shoot damage (Gerber et al., 2007; Johnson et al., 2007). Nevertheless, interactions between belowground herbivores and their hosts have been much less-studied than those of their aboveground counterparts. One of the reasons is the obscurity of root-herbivore interactions in the soil, which also means that root damage cannot be assessed as easily as shoot damage. Plants generally need to be sampled destructively to assess how much and where root feeding has occurred. To overcome this drawback and to non-invasively visualize the activities of root herbivores, techniques such as X-ray tomography and magnetic resonance imaging (MRI) have been successfully applied (Johnson et al., 2007; Jahnke et al., 2009). In addition, the development of new methods, for example, root area determination by using electrical potential measurements, may lead to novel approaches that help to monitor the feeding activities of root herbivores in vivo (Cao et al., 2010). Here, we present a novel approach to tracing the feeding activities of root herbivores that involves the detection of herbivoreinduced volatile organic compounds (VOCs) as a method for damage assessment (van Tol et al., 2001; Rasmann et al., 2005; Kaplan et al., 2008).

Despite the paucity of data, it has become evident that responses induced below ground in many respects resemble those found in aboveground plant-herbivore interactions. Just as in shoots, responses induced by herbivores may be both local and systemic, either within the root system or the whole plant, and comprise a wide range of defense compounds, such as alkaloids, phenolics, cardiac glycosides, and glucosinolates (Kaplan et al., 2008; Rasmann et al., 2009; van 
Dam, 2009; Hiltpold et al., 2011; Pierre et al., 2011a). In addition, root herbivory leads to the induction of volatile organic compounds (VOCs) that can be involved in indirect defenses below ground, by attracting the enemies of the attackers (van Tol et al., 2001; Rasmann et al., 2005; Pierre et al., 2011b). The role of VOCs might be even more important for belowground communities in the rhizosphere, as they serve herbivores and parasoitoids as cues for host localization in an environment where visual cues are lacking (Rasmann et al., 2005; van Dam, 2009). Indeed, recent studies have revealed various root-produced VOCs that play a role in plant-environment interactions. Maize roots attacked by larvae of the Western cornworm (Diabrotica virgifera virgifera) emit $(E)$ - $\beta$-caryophyllene, a sesquiterpenoid that attracts entomopathogenic nematodes (Rasmann et al., 2005), while Brassica plants infested with the larvae of the cabbage root fly (Delia radicum) emit sulfides that attract ground-dwelling predatory beetles (Ferry et al., 2007) and also various other VOCs that may be important cues for parasitoids of these root herbivores (Neveu et al., 2002; Pierre et al., 2011b).

Many compound classes that have been identified to play a role in belowground plant-environment interactions also are known from aboveground organs. Despite the overlap in defense strategies and compounds, there are striking differences in the VOCs produced by roots and shoots. For example, green leaf volatiles (GLVs) are commonly emitted by aboveground tissues of almost all higher plants after damage (Hansson et al., 1999; Barth and Schmid, 2001). However, they are not emitted when plant roots are artificially damaged or infested by herbivores (Steeghs et al., 2004), although they can be detected in minute amounts when plant roots are ground up (Matthias Erb, pers. comm.). Furthermore, the emission of sulfides, which often decreases when Brassica plants are damaged by aboveground herbivores (Blaakmeer et al., 1994; Geervliet et al., 1997), is strongly enhanced in roots of belowground-infested Brassica plants (Blaakmeer et al., 1994; Geervliet et al., 1997; Ferry et al., 2007; Soler et al., 2007). This suggests that root volatile "bouquets" may have a different composition from shoot VOC profiles. These differences may be related to differences in the performance of these compounds in soil environments. Properties such as polarity, boiling point, and solubility determine the degradation, adsorption to soil particles, and the distance over which a compound can disperse through soils, which in turn are important factors for the perception by soil biota. At present, the diversity of herbivore-induced VOCs released by aboveground plant organs appears to be greater than that in roots. It must be noted, however, that there still is a paucity of data on root specific VOCs, which leads to a bias, underestimating VOCs from roots.

In addition to local VOC responses, root herbivores also may induce systemic responses in shoots. The activities of root herbivores not only affect aboveground herbivores that are ovipositing and feeding on the leaves of the same plant (Bezemer et al., 2004; Anderson et al., 2011), but also alter the behavior of organisms at higher trophic levels - such as parasitoids and predators-foraging above ground (Rasmann and Turlings, 2007; Soler et al., 2007, this issue). The effect on aboveground higher trophic levels can either be mediated through changes in the host plant quality elicited in root-induced plants, such as proteinase inhibitors and the accumulation of secondary metabolites, or via changes in the volatile bouquets of root-induced plants that render these plants less attractive (Rasmann and Turlings, 2007; Soler et al., 2007). Changes in VOC emissions due to root herbivory can be detected in both belowground and aboveground tissues. Such root-induced changes in VOC emissions possibly can be exploited as indicators of root damage by herbivores without harvesting the plant. In order to do so, we need sensitive and non-invasive techniques that are capable of detecting minute changes in VOC emissions. Proton-transfer-reaction mass spectrometry (PTR-MS) is an on-line technique that allows the sensitive assessment of plant VOCs in real-time. In this review, we discuss the potential, possibilities, and pitfalls of using PTR-MS for the noninvasive and on-line analysis of VOCs induced by root herbivores in comparison to more traditional techniques applied in VOC research.

\section{VOC Analysis Using GC Platforms}

Plants emit substantial amounts of their assimilated carbon as VOCs: Up to $10 \%$ of their carbon assimilation can be released in this way (Peñuelas and Llusià, 2004). These emissions mainly consist of isoprene, a short chain (C5) hydrocarbon. The highly diverse class of higher isoprenoids $(>30,000$ different structures are described to date; Connolly and Hill, 1991) contributes smaller proportions, and their emission rates are often correlated with biotic and abiotic stressors. In the early days of chemical ecology, around three decades ago, the ability to investigate gaseous emissions from plants focused on the major peaks in the chromatogram. With the progress of analytical technologies, we are more and more approaching whole metabolome analyses, which is important, since minor compounds in the background of a complex volatile blend can contribute significantly to the biological activity of that blend (Mumm and Hilker, 2005; van Dam and Poppy, 2006).

The emission rates of plant VOCs usually are very low, ranging from a few nanograms to micrograms per gram plant dry weight, released per hour. At present, reported emission rates are particularly difficult to compare. In the chemical ecology literature, emission values are either presented in relation to plant weight (dry or fresh), or as relative emissions (e.g., Geervliet et al., 1997; Pierre et al., 2011b). This is, most likely, 
due to the fact that it would require many authentic standards to properly quantify each VOC in GC-MS analyses, and these are often difficult to obtain. Frequently, it also is a problem of units that prevents direct comparisons between published studies, especially between GC-MS and PTR-MS analyses.

A conversion of the unit commonly used for VOC emissions, in $\mathrm{ng} \cdot \mathrm{g}^{-1}$ [plant weight $] \cdot \mathrm{h}^{-1}$, into mixing ratios (in parts per billion volume, a common non SI-unit to report PTR-MS results) will give us this opportunity. We can approximately convert emissions by the following formula ${ }^{1}$ :

Emission $_{p p b v}=\frac{\text { Emission }_{g \cdot g^{-1}[D W] \cdot h^{-1}} * 24.5 \frac{1}{\mathrm{~mol}} * \mathrm{~m}_{\text {plant }}}{\mathrm{M}_{r} * \mathrm{~V}_{\text {air }}}$

Here, we give an example of this conversion for green leaf volatiles (GLVs), which are one of the most widespread VOC classes in the plant kingdom, at least above ground (Table 1). Because of the molecular weight, which has to be taken into account for the conversion, each compound contributes different ratios to the total emission, depending on the unit the value is described with. The GLV (Z)-3-Hexenol, for example, was emitted at a rate of $153.6 \mathrm{ng} \cdot \mathrm{g}^{-1}[\mathrm{dw}] \cdot \mathrm{h}^{-1}$, which is $43 \%$ of all GLVs in the herbivore treatment, but when expressed as a mixing ratio (ppbv), the same compound constitutes $53 \%$ of all GLVs (Table 1). Depending on the context, for example for insect physiology, the values might be biologically more informative when presented on a number-of-molecule basis, whereas in atmospheric chemistry the gram-based units might be preferred.

Due to low emission rates, the VOCs sampled from the plant headspace usually need to be pre-concentrated on adsorbents before they can be analyzed on gas chromatography (GC) platforms. Most commonly, plant VOCs are sampled on tubes filled with polymer materials, such as Tenax, Porapaq, Carbopack, and charcoal, or on solid phase micro-extraction fibers (SPME; D'Alessandro and Turlings, 2006; Tholl et al., 2006; Birkett, 2010). In view of this necessity to preconcentrate the sample before analysis, the procedure involves collection periods in the range of minutes to hours, which prevents highly time-resolved measurements of VOC emissions. Additionally, the sampling procedure may cause contaminations to be introduced when solvents are used to elute VOCs from the tubes before injection on the GC. With other sampling techniques this can be avoided. Using direct

\footnotetext{
${ }^{1}$ The formula assumes an ideal gas at $\mathrm{T}=25^{\circ} \mathrm{C}$ and $\mathrm{P}=1 \mathrm{~atm}$. For more precise conversions, parameters such as the true temperature during sampling, need to be accounted for. The molar volume of an ideal gas at these conditions is $24.51 \cdot \mathrm{mol}^{-1}$. $\mathbf{M}_{\mathbf{r}}$-relative molecular mass, DWdry weight, $\mathbf{m}_{\text {plant }}$ - total plant dry weight of sampled plant part, $\mathbf{V}_{\text {air }}$ total volume of air sampled.
}

thermodesorption (TD) tubes, the VOCs are thermally desorbed from the packing material and transferred directly to the GC injector port in the gaseous phase (e.g., Pierre et al., 2011b) In both cases, however, the relatively high temperatures, essential for rapid desorption or evaporation of the solvent in the injector port, may cause the VOCs to breakdown or to be converted into other components (de Kraker et al., 1998). Certain VOCs, such as sabinene and $\alpha$-pinene, also degrade to some extent as a result of reactions with the adsorbent surface (Rothweiler et al., 1991; Coeur et al., 1997). Moreover, depending on the packing materials of the sampling tubes, selective breakthrough of certain compounds, such as isoprene and other short-chain hydrocarbons, may occur, which makes the analysis less quantitative for these compounds (Dettmer et al., 2000). By contrast, PTR-MS has the potential to sample VOCs on-line and with high sensitivity (pptv), without the need for pre-concentration, thereby avoiding many of the above-mentioned drawbacks. Additionally, the instrument operates at much lower temperatures (around $50^{\circ} \mathrm{C}$ ) which reduces the formation of chemical artifacts (Hansel et al., 1995).

\section{Proton-Transfer-Reaction Mass-Spectrometry (PTR-MS)}

About 15 years ago, PTR-MS emerged as a powerful tool for monitoring VOCs. Whereas conventional MS technology is often based on electron ionization (EI), which results in extensive fragmentation providing rich ion fragments, PTR-MS relies on chemical ionization (CI), a soft ionization method with few or no ion fragments in the mass spectra. A detailed description of the PTR-MS technology has been published elsewhere (Hansel et al., 1995; de Gouw et al., 2003; Boamfa et al., 2004). Here, we briefly outline the main characteristics of the PTR-MS technology in so far as they are essential to be able to evaluate its opportunities and limitations for plant VOC analyses.

In PTR-MS, a neutral molecule is ionized via a CI reaction with $\mathrm{H}_{3} \mathrm{O}^{+}$. The ionized molecules typically form a protonated molecular ion $[\mathrm{M}+\mathrm{H}]^{+}$, in which $\mathrm{M}$ is the molecular mass of the parent molecule. Water or a mixture of water and helium is introduced and the $\mathrm{H}_{3} \mathrm{O}^{+}$ions are produced by a, mostly hollow, cathode discharge in the primary ion source (Fig. 1, no. 1; Boamfa et al., 2004). Thereafter, the $\mathrm{H}_{3} \mathrm{O}^{+}$ions enter the reaction chamber, the so-called drift tube (Fig. 1, no. 2), where they are driven by a homogenous electric field and will interact with the trace gas mixture that enters directly via an inlet at low gas flow rate $(\sim 0.5 \mathrm{l} / \mathrm{h})$. Typically, only molecules with a proton affinity higher than that of water $\left(>166.5 \mathrm{kcal} \mathrm{mol}^{-1}\right)$ will be ionized by proton-transfer-reactions with $\mathrm{H}_{3} \mathrm{O}^{+}$ions . Organic compounds such as aldehydes, ketones, alcohols, 
Table 1 Conversion of units commonly found in the literature for plant VOC emissions with an example of gypsy moth-induced green leaf volatiles (GLVs) of poplar (Populus trichocarpa), adapted from Danner et al. (2011)

\begin{tabular}{|c|c|c|c|c|c|}
\hline \multirow[t]{2}{*}{ Compound } & \multirow{2}{*}{$\begin{array}{l}\mathrm{M}_{\mathrm{r}}^{\mathrm{a}} \\
{\left[\mathrm{g} \cdot \mathrm{mol}^{-1}\right]}\end{array}$} & \multicolumn{2}{|c|}{ Emission $\left[\mathrm{ng} \cdot \mathrm{g}^{-1} \mathrm{DW}^{\mathrm{b}} \cdot \mathrm{h}^{-1}\right]$} & \multicolumn{2}{|c|}{ Emission $\left[\mathrm{ppbv}^{\mathrm{c}}\right]$} \\
\hline & & Control & Herb. & Control & Herb. \\
\hline (Z)-3-Hexenol & 100.2 & 9.4 & 153.6 & 0.16 & 2.61 \\
\hline (Z)-3-Hexenylacetate & 142.2 & 19.1 & 153 & 0.22 & 1.83 \\
\hline Hexyl acetate & 144.2 & 1.1 & 44.7 & 0.01 & 0.53 \\
\hline
\end{tabular}

${ }^{\mathrm{a}} \mathrm{M}_{\mathrm{r}}$-relative molecular weight

${ }^{\mathrm{b}} \mathrm{DW}$ - dry weight

${ }^{\mathrm{c}}$ ppbv—parts per billion volume

oxygenated aromatic and aliphatic compounds will be readily protonated (Warneke et al., 2003; Hartungen et al., 2004; Wisthaler et al., 2005; de Gouw and Warneke, 2007).

In addition to the normal proton-transfer-reaction, the $\mathrm{H}_{3} \mathrm{O}^{+}$and $[\mathrm{M}+\mathrm{H}]^{+}$ions can cluster with water molecules in the drift tube, complicating the interpretation of mass spectra. Since the proton affinity of the clusters is higher than that of water, the proton-transfer-reaction with a water cluster will be favored. An important part of the instrument that serves to reduce problems of cluster formation is the collision dissociation chamber (Fig. 1, no. 3). In this intermediate chamber, the cluster ions that leave the drift tube dissociate into a neutral moiety and the initial, protonated trace gas molecule $[\mathrm{M}+\mathrm{H}]^{+}$. Cluster formation can be reduced further by adapting the reaction conditions of the PTR-MS instrument for this purpose ( 2 mbar pressure and 120-140 Td field strength in the drift tube).

As described above, the proton-transfer results in few or no fragment ions for most trace gas compounds. Despite this general rule, fragment ions are still detected in the mass spectra for certain compounds, increasingly more with higher kinetic energy in the drift tube (Maleknia et al., 2007). Above all, the fragmentation pattern depends on the structure of the molecules. For example, alcohols break down easily and lose a water molecule via dehydration, whereas acetaldehyde or acetone is less likely to dissociate (Boamfa et al., 2004). Although there are extensive resources for EI fragmentation patterns [e.g., National Institute of Standards and Technology (NIST, USA) and Wiley (West Sussex, England)], these spectral libraries cannot be applied as a reference to PTR-MS, in view of the dissimilar ionization methods. Consequently, one needs to determine the fragmentation behavior of the VOCs under study either from the literature, or by reference measurements with authentic standards.

Another aspect to be considered is the back diffusion of air from the drift tube into the ion source, which leads to contaminant ions, such as $\mathrm{NO}^{+}$and $\mathrm{O}_{2}^{+}$(de Gouw and Warneke, 2007). PTR-MS of plant VOCs requires the amount of these ions to be reduced, because they transfer their charge to most VOCs without adding a proton, which complicates the identification of compounds. However, higher levels of $\mathrm{NO}^{+}$and $\mathrm{O}_{2}{ }^{+}$ions may also be beneficial for detecting specific compounds, such as sulfur-containing glucosinolate breakdown products (Crespo, 2012).

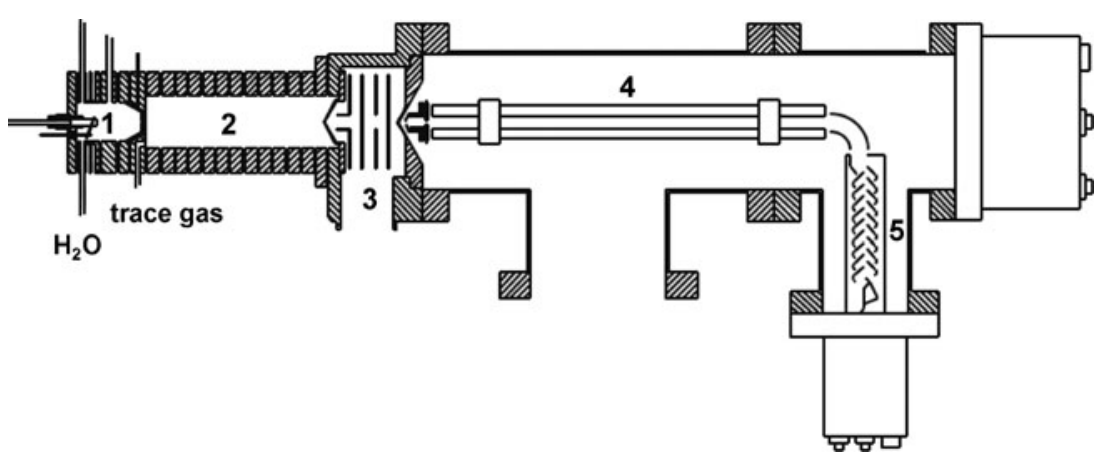

Fig. 1 Schematic representation of a typical PTR-MS. The instrument consists of an ion source (1) in which $\mathrm{H}_{3} \mathrm{O}^{+}$primary ions are produced, a drift tube (2), where the trace gases from samples are ionized by the proton-transfer reaction with $\mathrm{H}_{3} \mathrm{O}^{+}$ions, a collisional dissociation chamber (3), where cluster molecules dissociate, and the detection unit, where ions are mass filtered with a quadrupole mass filter (4) and quantified by a secondary electron multiplier (5) 


\section{Quantification and Identification of VOCs}

In PTR-MS, regular calibration with an authentic gas mixture is a prerequisite for reliable quantification of trace gases, for example, drift tube humidity can vary, which has an impact on the drift tube reactions. A typical example of a calibration gas mixture consists of acetaldehyde, acetone, isoprene, benzene, toluene, xylene, and $\alpha$-pinene (covering molecular masses from $32 \mathrm{amu}$ to $136 \mathrm{amu}$ ), each at a concentration of 1 ppmv (parts per million volume, $\pm 5 \%$ ). The calibration factors obtained for the fixed set of compounds in the certified gas mixture can be used to calculate the calibration factors of other compounds, by taking into account their collision rate constants, transmission efficiency factors, and fragmentation ratios. In this way, ion intensities (expressed as normalized counts per second, ncps) can be converted to absolute concentrations as gas mixing ratios (parts per billion volume, ppbv). PTR-MS can operate in two modes, namely the full mass scan and selective ion monitoring (SIM). The first scans the relative abundance of all detectable masses, and should be regarded as a fingerprint of a given trace gas sample (Steeghs et al., 2004). In contrast, the SIM mode is suitable for recording temporal changes in concentrations of specific trace gas molecules, pre-selected by their mass-to-charge ratios.

The major drawback with PTR-MS remains the identification of compounds, which is notoriously difficult, as each detected mass can either be associated with parent molecules, fragments of parent molecules, and water clusters, or a combination of these. Therefore, the identification of compounds measured by PTR-MS is mostly tentative. Nevertheless, if several compounds with the same nominal mass must be considered as possible candidates in a gas mixture, several methods to distinguish between these compounds can be employed. For example, water clusters can be easily distinguished from compounds undergoing the usual proton transfer reaction by varying the field strength in the drift tube $(\mathrm{E} / \mathrm{N})$. Association processes with water are quite sensitive to higher collision energies $(\mathrm{E} / \mathrm{N})$, thus, if the intensity of a signal decreases with higher $\mathrm{E} / \mathrm{N}$, the signal is contributed by a compound associated with one or more water molecules.

In the same way, the abundance of stable isotopes can provide further information about the identity of a compound. The probability of ${ }^{13} \mathrm{C}$ incorporation into a molecule rises in a linear fashion with the number of carbon atoms in that molecule. For example, with the natural ${ }^{13} \mathrm{C}$ abundance of $1.1 \%$, a molecule containing 5 carbon atoms, such as isoprene $(M=68)$ has a chance of $5.5 \%$ to contain exactly one ${ }^{13} \mathrm{C}$. With PTR-MS, isoprene is detected as $\mathrm{C}_{5} \mathrm{H}_{9}{ }^{+}$at $\mathrm{m} /$ $z=69$, however, this signal also can be attributed to a watermethanol cluster-ion, $\mathrm{CH}_{3} \mathrm{OH}\left(\mathrm{H}_{2} \mathrm{O}\right) \mathrm{H}^{+}$. If the ratio between $\mathrm{m} / \mathrm{z}=69$ and its isotope at $\mathrm{m} / \mathrm{z}=70$ indicates a ${ }^{13} \mathrm{C}$ abundance close to the expected value for a 5 -carbon compound (5.5\%) the signal measured at $m / z=69$ is more likely to be derived from isoprene. Additionally, in complex gas mixtures, such as the ones derived from plant headspaces or human breath, it is common practice to proceed along these lines for compound identification (Lindinger et al., 1998; Crespo et al., 2011). Additional information about the identity of the molecule species also can be obtained from any other element with stable isotopes. Examples are nitrogen with an isotopic ${ }^{15} \mathrm{~N} /{ }^{14} \mathrm{~N}$ ratio of $0.366 \%$, hydrogen with a ${ }^{2} \mathrm{H} /{ }^{1} \mathrm{H}$ ratio of $0.015 \%$, and sulfur with a ${ }^{34} \mathrm{~S} /{ }^{32} \mathrm{~S}$ ratio of $4.21 \%$. However, ion-trap-based PTR-MS with the ability to perform MS/MS, TOF-based PTR-MS with high mass resolution, or coupling of GC with PTR-MS, are the preferred options for the unambiguous identification of compounds (Joó et al., 2010).

Basically, there are two main issues associated with the identification of compounds. First of all, the signal of the parent and fragment ions (isobaric ions) from different compounds can be superimposed on one $\mathrm{m} / \mathrm{z}$ in the spectra without the possibility of discrimination. This complicates straightforward identification of VOCs in complex mixtures. Moreover, compounds with different structures but the same molecular mass appear at the same $\mathrm{m} / \mathrm{z}$ signal and cannot be distinguished with a quadrupole mass filter (e.g., different monoterpenoids). To overcome these limitations, several new technologies have been developed. Combining PTR-MS with a GC, in which the VOCs are first separated by their retention time in the GC and then detected one by one by PTR-MS, avoids the overlap of different compounds and fragments (Warneke et al., 2003). Proton-transfer-reaction ion-trap mass spectrometry (PIT-MS) is another promising development to differentiate between different compounds with similar masses (Steeghs et al., 2004). This technique has characteristics similar to those of the PTR-MS, except that an ion trap is used, instead of a quadrupole as a mass analyzer. In PIT-MS, collision-induced dissociation (CID) is performed inside the ion trap, allowing different compounds with an identical mass to be differentiated by their fragmentation pattern (MS/MS). This approach enables, for example, the identification of different terpenoids and their oxygenated derivatives. Very promising is the recent development of a high-resolution time-of-flight (TOF) based system, PTR-TOF-MS, which is able to distinguish between isobaric molecules and allows unambiguous identification based on exact masses (Blake et al., 2004; Ennis et al., 2005; Graus et al., 2010). In classical PTR-MS, only one type of precursor ion $\left(\mathrm{H}_{3} \mathrm{O}^{+}\right)$is commonly employed to ionize compounds. In addition, other ions such as $\mathrm{NO}^{+}$and $\mathrm{O}_{2}^{+}$can be produced in the ion source with the switchable reagent ions (SRI) technology (Jordan et al., 2009). These primary ions allow compounds with proton affinities lower than that of water (e.g., halogenated hydrocarbons) to be detected and isomeric compounds to be distinguished. 


\section{Applications of PTR-MS for Biological Research}

Since its development, PTR-MS has found many applications in a wide range of fields, including medicine (Cristescu et al., 2011), environmental sciences and atmospheric chemistry (de Gouw and Warneke, 2007; Bamberger et al., 2010; Ruuskanen et al., 2011), food monitoring (Raseetha et al., 2011), monitoring for safety and security at the workspace (Hansel et al., 1995), VOC emissions from plants during various abiotic stress conditions (Gray et al., 2010; Ruuskanen et al., 2011), and, most importantly in the context of this review, in understanding the chemistry of plant-herbivore interactions (Schaub et al., 2010; Brilli et al., 2011).

The VOC emissions resulting from plant-herbivore interactions are highly complex and dynamic. PTR-MS offers the opportunity to follow these processes in real-time. It has proven extremely difficult to use conventional sampling techniques and GC platforms to follow the fast conversion processes taking place in the lipoxygenase pathway (LOX) immediately after leaf wounding. With PTR-MS, this process has been studied at a high time-resolution, which yielded new insight into the regulation of this pathway (Fall et al., 1999; D'Auria et al., 2007). PTR-TOF-MS enabled the timing of the enzymatic conversions in the LOX pathway to be elucidated in mechanically wounded Dactlylis glomerata plants (Brilli et al., 2011). The conversion processes were analyzed from the initial membrane breakdown, resulting in fast emissions of C6 aldehydes, until the somewhat slower conversion of the intermediate C6 alcohols into hexyl and hexenyl acetates. Mobile PTR-MS equipment also has been used to investigate the timing of herbivore-induced green leaf volatiles, monoterpenoids, and sesquiterpenoids in poplar trees in the field (Schaub et al., 2010) and to monitor VOC emissions from complex vegetations such as grasslands or forest canopies (Davison et al., 2008; Bamberger et al., 2010; Ruuskanen et al., 2011).

However, the examples above all relate to plant volatiles induced above ground. To our knowledge, only one study has investigated root VOCs by means of PTR-MS. This study analyzed VOC emissions of in vitro cultured Arabidopsis roots after infection with a pathogen, Pseudomonas syringae, and the aphid Diuraphis noxia. The infections induced several simple metabolites, such as acetic acid, acetone, and ethanol, and a single monoterpenoid, namely 1,8-cineole (Steeghs et al., 2004). Interestingly, GLVs were not found to be released by damaged Arabidopsis roots. As the roots were grown in vitro, however, the question remains how representative the herbivore-induced responses observed in this experiment are for plants that are growing in the soil.

Therefore, we present two examples of preliminary PTRMS results on herbivore-induced root responses in Brassica species obtained with a custom-made PTR-MS described in detail in Boamfa et al. (2004). We monitored VOCs emanating from roots of potted turnip plants (Brassica rapa subsp. rapa var. Nancy) during infestation with a belowground herbivore, the larvae of the cabbage root fly (Delia radicum). The root headspace of infested and non-infested plants was sampled from a cuvette fitted around the base of the stem (Fig. 2). The two parts of the cuvette were sealed together with Terostat IX (Henkel, UK), a solvent-free, rubber-based sealant (Crespo, 2012) to prevent ambient air from entering. During measurements, an excess flow of hydrocarbon-free air into the cuvette was maintained, similar to a typical dynamic headspace collection setup (Tholl et al., 2006). The resulting mass scan (Fig. 3) shows that the intensities of several molecular masses are enhanced in root fly infested $B$. rapa roots, the identities of which were confirmed by Crespo (2012) by additional GC-MS analysis and PTR-MS measurements of authentic standards. The induced intensities were detected in several structurally related sulfides, some of which have been shown to be induced in more than one Brassica species after root fly feeding, and which are exploited as cues by parasitoids and predators (Ferry et al., 2007; Soler et al., 2007). The mass-charge ratios representing dimethyl disulfide (DMDS; $m / z=63$ ) and dimethyltrisulfide (DMTS; $m / z=95$ ) displayed considerable increases in emission rates due to herbivore feeding. In addition, we also found that the biosynthetically related compound methanethiol $(m / z=49)$ was emitted at higher rates when root fly larvae were feeding. Previous GC analyses have not detected methanethiol, which might originate from the compound selectivity of the adsorbents that have been used for collection. Interestingly, we also found a considerable increase in $m / z=60$, which is related to glucosinolate breakdown products (Crespo, 2012). This is a typical characteristic of members of the Brassicaceae after tissue damage. After disruption of the cells, a separately stored enzyme (myrosinase) converts the glucosinolates that are stored in the vacuoles into toxic and volatile products, such as isothiocyanates and nitriles (Hopkins et al., 2009). After activation of this two-component defense mechanism, the volatile conversion products are detected in the headspace of damaged plants (Soler et al., 2007; Pierre et al., 2011b). Our preliminary

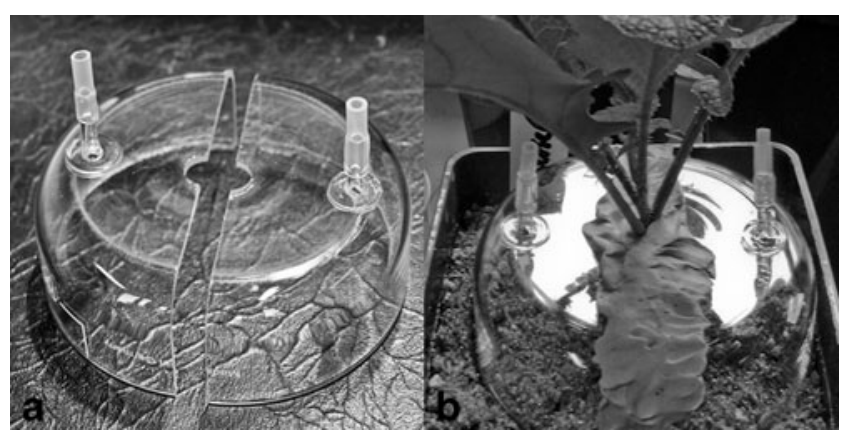

Fig. 2 Cuvette used for dynamic headspace collections from plant roots. a the cuvette which consists of two parts with an air in- and outlet, respectively. b cuvette fitted together and tightened with a rubber-based sealant 
experiment shows that glucosinolate conversion products also emanate from roots, damaged by soil herbivores.

As another example, we monitored the induction of VOCs in B. juncea roots after infestation with Delia radicum in realtime and compared it to a control treatment (Fig. 4). We followed the emission of root VOCs for several hours in SIM mode, starting immediately after ten actively feeding second instar larvae were added to the roots. Based on the previous example, we chose to record specifically the masses which correlate to the three sulfides from the previous experiment and the mass 60, all of which already revealed differences between the treatments in scan mode (Fig. 3). Initially, we observed a low emission rate of only several ppbv for these compounds, which steadily increased with longer feeding times of the root flies (Fig. 4). In control plants, the VOC emissions remained at a very low level, which allowed a clear distinction between control and infested plants within a few hours after infestation. We suggest that further development of PTR-MS methods and sampling set-ups might provide us with the tools to correlate the intensities of the VOC emissions directly to the amount of herbivore damage in a quantitative manner. Possibly, the PTR-MS emission patterns can be used to assess the infestation level of root herbivores or to assess the time point when they stop feeding or start pupating by exploiting certain VOC related masses as non-invasive markers.

\section{Conclusions}

As outlined, PTR-MS has in the recent years opened an avenue for new insight into fast changing, highly dynamic processes involved in plant VOC emissions caused by plant-

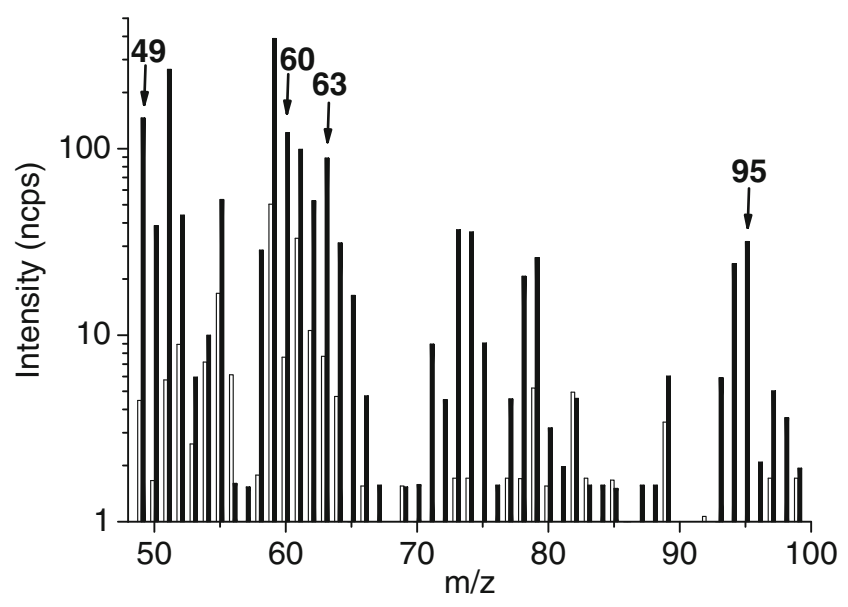

Fig. 3 Identification of enhanced signals at masses correlated to volatile organic compounds (VOCs) from Brassica rapa spp. rapa Nancy by PTR-MS (scan mode) after root herbivory by Delia radicum (black bars) vs. control plants (white bars). [ncps]—normalized counts per second, $m / z=49$-methanethiol, $m / z=60$ - related to glucosinolate breakdown products, $m / z=63$ - dimethylsulfide (DMS), $m / z=95$ dimethyldisulfide (DMDS)

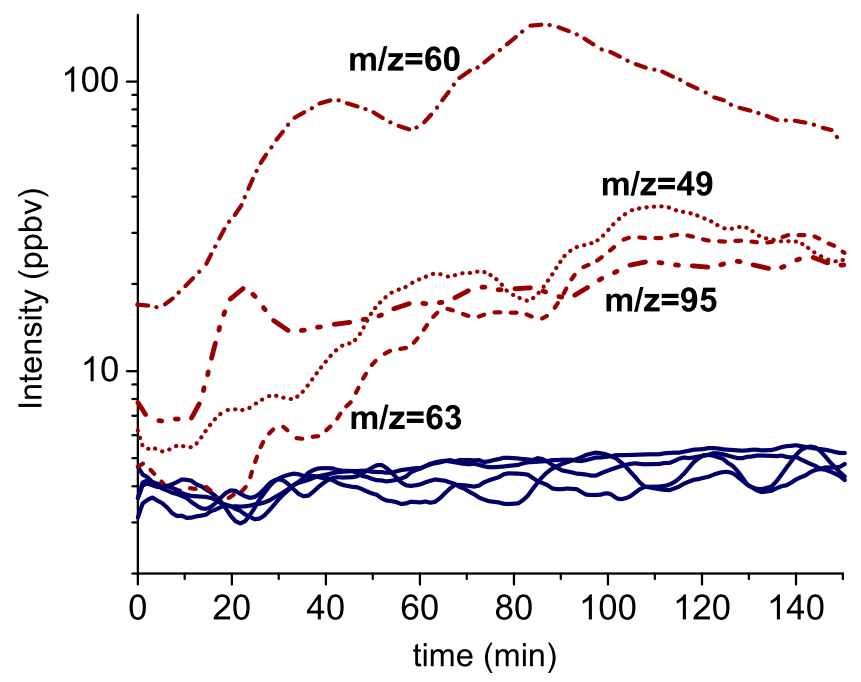

Fig. 4 Temporal dynamics of volatile organic compound emission from Brassica juncea after root herbivory by Delia radicum (broken lines) and a control without damage (continuous lines) by PTR-MS (SIM mode). $m / z=49$ - methanethiol, $m / z=60$-related to glucosinolate breakdown products, $m / z=63$ - dimethylsulfide (DMS), $m / z=95$ dimethyldisulfide (DMDS)

environment interactions. Here, we show that, due to its sensitivity and the ability to record real-time responses, PTR-MS is an excellent technique to non-invasively trace the feeding activities of cryptically feeding root herbivores by measuring VOC emissions from the root headspace. Certainly, PTR-MS also has its practical and technical limitations. Besides difficulties in linking masses without doubt to compounds, many quadrupole-based systems lack sensitivity in the higher mass range (above $120 \mathrm{amu}$ ), which is relevant for plant-herbivore interactions, as many biologically important compounds, such as several isothiocyanates or generally hemiterpenoids and sesquiterpenoids are difficult to detect. These shortcomings can be overcome partially by combining on-line sampling with PTR-MS and off-line GC-MS methods, or by use of high sensitivity PTR-MS instruments with mass analyzers, such as distinctive quadrupoles, triple quadrupole technology, ion trap, or time-of-flight, which can provide sensitivity also in the higher mass range (Tani et al., 2003; Kim et al., 2009). We expect that the innovative and fast-evolving field of MS technologies will result in further improvements regarding sensitivity and mass resolution. Consequently, PTR-MSbased technologies may soon approach detection limits even closer to the sensitivity of insect antennae. A recently developed sensor, for example, which uses antennae of Colorado potato beetles (Leptinotarsa decemlineata) or of jewel beetles (Phaenops cyanea), demonstrates that insect antennae are capable of detecting, for instance, the GLV (Z)-3-hexen-1-ol at around 1 ppmv and 1 pptv, for the two species, respectively. Compared to that, the detection limits in PTR-MS already are in a similar range of several parts per trillion volume, depending on the properties of the instrumentation. 
Finally, time-resolved and sensitive on-line sampling of rootinduced volatiles with PTR-MS will certainly contribute to our understanding of the role of VOCs in belowground multitrophic interactions. In particular, linking real-time responses in the emission of VOCs to immediate behavioral responses of herbivores, and to the higher trophic levels of parasitoids and predators will unravel further details of the VOC 'language' among plants and between plants and insects. This may be achieved by 'sniffing out' the VOCs in parallel with olfactometer assays, a prime example of which is the development of a sixarm olfactometer, simultaneously equipped with a VOC sampling unit (Turlings et al., 2004). In a similar way, coupling PTRMS analyses with microbial bioassays may help to disentangle the impact of belowground plant VOCs on other soil organisms, such as pathogens and microbes (Effmert et al., this issue). In addition to that, new approaches in multivariate statistical analyses will facilitate discrimination of biologically meaningful information from noise contained in these increasingly complex mixtures (van Dam and Poppy, 2006; Jansen et al., 2010) with steadily increasing numbers of compounds due to the rising sensitivity of instrumentation. Last but not least, improving our methods for non-destructive plant VOC sampling from soil environments will complement the knowledge we have gained already from aboveground plant organs, with further discrepancies and similarities being discovered between the two compartments of plants living apart together. With a more complete perspective on plant VOCs and their biological roles, we might later be able to complement our current perceptions of plant defenses, adapted to a perspective of the whole plant.

Acknowledgements We thank the editors for the invitation to write this review. AM Cortesero and A Ferry, University of Rennes, France, are thanked for permission to use unpublished data in Fig. 3. Their work was supported by EU-FP6-Infrastructures-5, project FP6-026183 "Life Science Trace Gas Facility". HD is supported by a grant in the ESF-EuroVOL program funded by the Netherlands Organisation for Scientific Research (NWO- ALW), grant number 855.01.172. We also thank John D'Auria and Suzanne Haaijer for helpful comments on an earlier version of this manuscript.

Open Access This article is distributed under the terms of the Creative Commons Attribution License which permits any use, distribution, and reproduction in any medium, provided the original author(s) and the source are credited.

\section{References}

Anderson, P., SAdek, M. M., and Wäckers, F. L. 2011. Root herbivory affects oviposition and feeding behavior of a foliar herbivore. Behav. Ecol. 22:1272-1277.

Bamberger, I., Hortnagl, L., Schnitzhofer, R., Graus, M., RuUskanen, T. M., Muller, M., DunKL, J., Wohlfahrt, G., and HANSEL, A. 2010. BVOC fluxes above mountain grassland. Biogeosciences 7:1413-1424.

BARTH, F. G. and SCHMID, A. 2001. Ecology of sensing. Springer, Berlin.
Bezemer, T. M., WAgenaAR, I. R., VAN DAM, N. M., VAN DER PutTEN, W. H., and WÄCKERS, F. L. 2004. Above- and belowground terpenoid aldehyde induction in cotton, Gossypium herbaceum, following root and leaf injury. J. Chem. Ecol. 30:53-67.

BIRKETT, M. A. 2010. The chemistry of plant signalling, pp. 21-42, in F. Baluška and V. Ninkovic (eds.), Plant communication from an ecological perspective. Springer, Berlin, Heidelberg.

BlaAkmeer, A., Geervliet, J. B. F., van LoOn, J. J. A., Posthumus, M. A., VAN BEEK, T. A., and DE GROOT, A. 1994. Comparative headspace analysis of cabbage plants damaged by two species of Pieris caterpillars - consequences for in-flight host location by Cotesia parasitoids. Entomol. Exp. Appl. 73:175-182.

Blake, R. S., Whyte, C., Hughes, C. O., Ellis, A. M., and Monks, P. S. 2004. Demonstration of proton-transfer reaction time-offlight mass spectrometry for real-time analysis of trace volatile organic compounds. Anal. Chem. 76:3841-3845.

Boamfa, E. I., Steeghs, M. M. L., Cristescu, S. M., and Harren, F. J. M. 2004. Trace gas detection from fermentation processes in apples; an intercomparison study between proton-transferreaction mass spectrometry and laser photoacoustics. Int. J. Mass Spectrom. 239:193-201.

Brilli, F., Ruuskanen, T. M., Schnitzhofer, R., Muller, M., BReitenlechner, M., BitTNeR, V., WOHLFAhrT, G., LORETO, F., and HANSEL, A. 2011. Detection of plant volatiles after leaf wounding and darkening by proton transfer reaction "time-offlight" mass spectrometry (PTR-TOF). PLoS One 6:e20419.

CaO, Y., Repo, T., Silvennoinen, R., Lehto, T., and Pelkonen, P. 2010. An appraisal of the electrical resistance method for assessing root surface area. J. Exp. Bot. 61:2491-2497.

Coeur, C., JACOB, V., Denis, I., and Foster, P. 1997. Decomposition of $\alpha$-pinene and sabinene on solid sorbents, tenax TA and carboxen. J. Chromatogr. A 786:185-187.

Connolly, J. D. and HiLl, R. A. 1991. Dictionary of terpenoids. Chapman and Hall, London.

CRESPO, E. 2012. Proton transfer reaction-mass spectrometry, applications in life sciences. Radboud University $\mathrm{PhD}$ dissertation, Nijmegen.

Crespo, E., Cristescu, S. M., de Ronde, H., KuijPer, S., Kolk, A. H. J., Anthony, R. M., and Harren, F. J. M. 2011. Proton transfer reaction mass spectrometry detects rapid changes in volatile metabolite emission by Mycobacterium smegmatis after the addition of specific antimicrobial agents. J. Microbiol. Methods 86:8-15.

Cristescu, S. M., Gietema, H. A., Blanchet, L., Kruitwagen, C. L. J. J., MunniK, P., Klaveren, R. J. V., Lammers, J. W. J., Buydens, L., HARREN, F. J. M., and ZANEN, P. 2011. Screening for emphysema via exhaled volatile organic compounds. J. Breath Res. 5:046009.

D'Alessandro, M. AND Turlings, T. C. J. 2006. Advances and challenges in the identification of volatiles that mediate interactions among plants and arthropods. Analyst 131:24-32.

D'Auria, J. C., Pichersky, E., Schaub, A., Hansel, A., and GERSHENZON, J. 2007. Characterization of a BAHD acyltransferase responsible for producing the green leaf volatile (Z)-3-hexen1-yl acetate in Arabidopsis thaliana. Plant J. 49:194-207.

Danner, H., Boeckler, G. A., Irmisch, S., Yuan, J. S., Chen, F., GERSHNZON, J., UnSiCKer, S. B., and KolLner, T. G. 2011. Four terpene synthases produce major compounds of the gypsy moth feeding-induced volatile blend of Populus trichocarpa. Phytochemistry 72:897-908.

Davison, B., Brunner, A., AMmann, C., Spirig, C., Jocher, M., and NefTEL, A. 2008. Cut-induced VOC emissions from agricultural grasslands. Plant Biol. 10:76-85.

DE Gouw, J. and WARNEKE, C. 2007. Measurements of volatile organic compounds in the earths atmosphere using protontransfer-reaction mass spectrometry. Mass Spectrom. Rev. 26:223-257. 
De Gouw, J., Warneke, C., Karl, T., Eerdekens, G., VAn der VeEn, C., and FALL, R. 2003. Sensitivity and specificity of atmospheric trace gas detection by proton-transfer-reaction mass spectrometry. Int. J. Mass Spectrom. 223:365-382.

de Kraker, J. W., Franssen, M. C. R., De Groot, A., Konig, W. A., and BOUWMEESTER, H. J. 1998. (+)-Germacrene A biosynthesisthe committed step in the biosynthesis of bitter sesquiterpene lactones in chicory. Plant Physiol. 117:1381-1392.

DetTmer, K., KNobloch, T., and Engewald, W. 2000. Stability of reactive low boiling hydrocarbons on carbon based adsorbents typically used for adsorptive enrichment and thermal desorption. Fresen. J. Anal. Chem. 366:70-78.

EFFMERT, U., KALDERAS, J., WARNKE, R., and PIEChULla, B. Volatile mediated interactions between bacteria and fungi in the soil. $J$. Chem. Ecol., this issue.

EnNis, C. J., Reynolds, J. C., Keely, B. J., and CARPENTER, L. J. 2005. A hollow cathode proton transfer reaction time of flight mass spectrometer. Int. J. Mass Spectrom. 247:72-80.

FAll, R., KARl, T., HANSEl, A., Jordan, A., and Lindinger, W. 1999. Volatile organic compounds emitted after leaf wounding: on-line analysis by proton-transfer-reaction mass spectrometry. $J$. Geophys. Res.-Atmos. 104:15963-15974.

Ferry, A., Dugravot, S., Delattre, T., Christides, J. P., Auger, J., Bagneres, A. G., Poinsot, D., and Cortesero, A. M. 2007. Identification of a widespread monomolecular odor differentially attractive to several Delia radicum ground-dwelling predators in the field. J. Chem. Ecol. 33:2064-2077.

Geervliet, J. B. F., Posthumus, M. A., Vet, L. E. M., and Dicke, M. 1997. Comparative analysis of headspace volatiles from different caterpillar-infested or uninfested food plants of pieris species. $J$. Chem. Ecol. 23:2935-2954

Gerber, E., Hinz, H. L., and Blossey, B. 2007. Interaction of specialist root and shoot herbivores of Alliaria petiolata and their impact on plant performance and reproduction. Ecol. Entomol. 32:357-365.

Graus, M., MÜller, M., and HANSEl, A. 2010. High resolution PTRTOF: quantification and formula confirmation of VOC in real time. J. Am. Soc. Mass Spectr. 21:1037-1044.

Gray, C. M., Monson, R. K., and FiERER, N. 2010. Emissions of volatile organic compounds during the decomposition of plant litter. J. Geophys. Res. 115:G03015.

Hansel, A., Jordan, A., Holzinger, R., Prazeller, P., Vogel, W., and LINDINGER, W. 1995. Proton transfer reaction mass spectrometry: on-line trace gas analysis at the ppb level. Int. J. Mass Spectrom. 149/150:609-619.

HANSSON, B. S., LARSSON, M. C., and LeAL, W. S. 1999. Green leaf volatile-detecting olfactory receptor neurones display very high sensitivity and specificity in a scarab beetle. Physiol. Entomol. 24:121-126.

Hartungen, E. V., Wisthaler, A., Mikoviny, T., Jaksch, D., BoscainI, E., DunPhy, P. J., and MÄrK, T. D. 2004. Protontransfer-reaction mass spectrometry (PTR-MS) of carboxylic acids: determination of Henry's law constants and axillary odour investigations. Int. J. Mass Spectrom. 239:243-248.

Hiltpold, I., Erb, M., Robert, C. A. M., and Turlings, T. C. J. 2011. Systemic root signalling in a belowground, volatilemediated tritrophic interaction. Plant Cell Environ. 34:12671275.

HOPKINS, R. J., VAN DAM, N. M., and VAN LOON, J. J. A. 2009. Role of glucosinolates in insect-plant relationships and multitrophic interactions. Annu. Rev. Entomol. 54:57-83.

JahnKe, S., Menzel, M. I., van Dusschoten, D., Roeb, G. W., Buhler, J., Minwuyelet, S., Blumler, P., TEMPERTON, V. M., Hombach, T., Streun, M., et al. 2009. Combined MRI-PET dissects dynamic changes in plant structures and functions. Plant J. 59:634-644.
Jansen, J. J., Smit, S., Hoefsloot, H. C. J., and Smilde, A. K. 2010. The photographer and the greenhouse: how to analyse plant metabolomics data. Phytochemical Anal 21:48-60.

Johnson, S. N., Crawford, J. W., Gregory, P. J., Grinev, D. V., MANKIN, R. W., MASTERS, G. J., MurRaY, P. J., WALL, D. H., and ZHANG, X. X. 2007. Non-invasive techniques for investigating and modelling root-feeding insects in managed and natural systems. Agr. Forest Entomol. 9:39-46.

Joó, É., Dewulf, J., Demarcke, M., Amelynck, C., Schoon, N., MÜller, J. F., ŠIMPRAGA, M., StePPe, K., and VAN LANGENHOVE, H. 2010. Quantification of interferences in PTR-MS measurements of monoterpene emissions from Fagus sylvatica L. using simultaneous TD-GC-MS measurements. Int. J. Mass. Spectrom. 291:90-95.

Jordan, A., Haidacher, S., HANel, G., Hartungen, E., MärK, L., SEeHAuser, H., SCHOTTKOWSKY, R., SUlzer, P., and MÄrk, T. D. 2009. A high resolution and high sensitivity proton-transferreaction time-of-flight mass spectrometer (PTR-TOF-MS). Int. J. Mass Spectrom. 286:122-128.

Kaplan, I., Halitschke, R., Kessler, A., Sardanelli, S., and DENNO, R. F. 2008. Constitutive and induced defenses to herbivory in above- and belowground plant tissues. Ecology 89:392-406.

Kim, S., Karl, T., Helmig, D., Daly, R., Rasmussen, R., and GUENTHER, A. 2009. Measurement of atmospheric sesquiterpenes by proton transfer reaction-mass spectrometry (PTR-MS). Atmos. Meas. Tech. 2:99-112.

LINDINGER, W., HANSEl, A., and JoRDAN, A. 1998. On-line monitoring of volatile organic compounds at pptv levels by means of proton-transfer-reaction mass spectrometry (PTR-MS) medical applications, food control and environmental research. Int. J. Mass Spectrom. 173:191-241.

MaleKniA, S. D., Bell, T. L., and AdAMS, M. A. 2007. PTR-MS analysis of reference and plant-emitted volatile organic compounds. Int. J. Mass Spectrom. 262:203-210.

Mumm, R. and HilKeR, M. 2005. The significance of background odour for an egg parasitoid to detect plants with host eggs. Chem. Senses 30:337-343.

Neveu, N., Grandgirard, J., Nenon, J. P., And Cortesero, A. M. 2002. Systemic release of herbivore-induced plant volatiles by turnips infested by concealed root-feeding larvae Delia radicum L. J. Chem. Ecol. 28:1717-1732.

PeÑUelas, J. and LlusiÀ, J. 2004. Plant VOC emissions: making use of the unavoidable. Trends Ecol. Evol. 19:402-404.

Pierre, P. S., Dugravot, S., Cortesero, A.-M., Poinsot, D., RAAIJMAKERS, C. E., and HASSAN, H. M. 2011a. Broccoli and turnip plants display contrasting responses to belowground induction by Delia radicum infestation and phytohormone applications. Phytochemistry 73:42-50.

Pierre, P. S., Jansen, J. J., HordiJK, C. A., VAN Dam, N. M., Cortesero, A.-M., and Dugravot, S. 2011b. Differences in volatile profiles of turnip plants subjected to single and dual herbivory above- and belowground. J. Chem. Ecol. 37:368-377.

Raseetha, S., Heenan, S. P., Oey, I., Burritt, D. J., and Hamid, N. 2011. A new strategy to assess the quality of broccoli (Brassica oleracea L. italica) based on enzymatic changes and volatile mass ion profile using Proton Transfer Reaction Mass Spectrometry (PTR-MS). Innov. Food Sci. Emerg. 12:197-205.

RASMANN, S. and TuRLingS, T. C. J. 2007. Simultaneous feeding by aboveground and belowground herbivores attenuates plant-mediated attraction of their respective natural enemies. Ecol. Lett. 10:926-936.

Rasmann, S., KÖllner, T. G., Degenhardt, J., HiltPold, I., TOEPFER, S., KUHLMANN, U., GERSHENZON, J., and TuRLINGS, T. C. J. 2005. Recruitment of entomopathogenic nematodes by insect-damaged maize roots. Nature 434:732-737.

Rasmann, S., Agrawal, A. A., Cook, S. C., and Erwin, A. C. 2009. Cardenolides, induced responses, and interactions between above- 
and belowground herbivores of milkweed (Asclepias spp.). Ecology 90:2393-2404.

Rothweiler, H., WÄGer, P. A., and Schlatter, C. 1991. Comparison of Tenax Ta and Carbotrap for sampling and analysis of volatile organic compounds in air. Atmos. Environ. B-Urb. 25:231-235.

RuUSKanen, T. M., MÜLler, M., SCHNitZHOFER, R., KARL, T., GRAUS, M., BAmberger, I., HÖrtnagl, L., Brilli, F., Wohlfahrt, G., and HANSEL, A. 2011. Eddy covariance VOC emission and deposition fluxes above grassland using PTR-TOF. Atmos. Chem. Phys. 11:611-625.

Schaub, A., Blande, J. D., Graus, M., OKsanen, E., Holopainen, J. K., and HANSEL, A. 2010. Real-time monitoring of herbivore induced volatile emissions in the field. Physiol. Plant. 138:123133.

Soler, R., Van Der Putten, W. H., Harvey, J. A., Vet, L. E. M., DICKE, M., and BEZEMER, T. M. Root herbivore effects on aboveground multitrophic interactions: patterns, processes and mechanisms. J. Chem. Ecol., this issue.

Soler, R., Harvey, J. A., Kamp, A. F. D., Vet, L. E. M., Putten, W. H. V. D., Dam, N. M. V., Stuefer, J. F., Gols, R., HordiJK, C. A., and BEZEMER, T. M. 2007. Root herbivores influence the behaviour of an aboveground parasitoid through changes in plant-volatile signals. Oikos 116:367-376.

Steeghs, M., Bais, H. P., DE Gouw, J., Goldan, P., Kuster, W., Northway, M., Fall, R., and Vivanco, J. M. 2004. Protontransfer-reaction mass spectrometry as a new tool for real time analysis of root-secreted volatile organic compounds in Arabidopsis. Physiol. Plant. 135:47-58.
Tani, A., Hayward, S., and HewitT, C. N. 2003. Measurement of monoterpenes and related compounds by proton transfer reactionmass spectrometry (PTR-MS). Int. J. Mass Spectrom. 223224:561-578.

Tholl, D., Boland, W., Hansel, A., Loreto, F., Rose, U. S. R., AND SCHNITZLER, J.-P. 2006. Practical approaches to plant volatile analysis. Plant $J$. 45:540-560.

Turlings, T. C. J., Davison, A. C., and TAmò, C. 2004. A six-arm olfactometer permitting simultaneous observation of insect attraction and odour trapping. Physiol. Entomol. 29:45-55.

VAN DAM, N. M. 2009. Belowground herbivory and plant defenses. Annu. Rev. Ecol. Syst. 40:373-391.

VAN DAM, N. M. and POPPY, G. M. 2006. Why plant volatile analysis needs bioinformatics-detecting signal from noise in increasingly complex profiles. Plant Biol. 10:29-37.

VAN TOL, R. W. H. M., VAN DER SOMMEN, A. T. C., BOFF, M. I. C., VAN Bezooijen, J., SABELIS, M. W., and SMits, P. H. 2001. Plants protect their roots by alerting the enemies of grubs. Ecol. Lett. 4:292-294.

Warneke, C., De Gouw, J. A., Kuster, W. C., Goldan, P. D., and FALL, R. 2003. Validation of atmospheric VOC measurements by proton-transfer-reaction mass spectrometry using a gaschromatographic preseparation method. Environ. Sci. Technol. 37:2494-2501.

Wisthaler, A., Tamas, G., Wyon, D. P., Strom-Tejsen, P., Space, D., Beauchamp, J., Hansel, A., Mark, T. D., and Weschler, C. J. 2005. Products of ozone-initiated chemistry in a simulated aircraft environment. Environ. Sci. Technol. 39:4823-4832. 